\title{
Planning of different types of distributed generation with seasonal mixed load models
}

\author{
Rajendra Prasad Payasi ${ }^{1 *}$, Asheesh K. Singh ${ }^{1}$, Devender Singh ${ }^{2}$ \\ ${ }^{I^{*}}$ Department of Electrical Engineering, Motilal Nehru National Institute of Technology Allahabad, INDIA \\ ${ }^{2}$ Department of Electrical Engineering, Institute of Technology BHU, Varanasi, INDIA \\ *Corresponding Author: e-mail: payasirp@rediffmail.com, Mobile no: +91-9839835741
}

\begin{abstract}
The comparison of different types of distributed generation (DG) may help for appropriate selection of type of DG for distributed generation planning (DGP) in distribution system for various load scenario. The load on each bus of distribution system may be, in practice, the composition of industrial, residential, and commercial types of load which may also vary with seasonal day, and night. Therefore, in this paper the seasonal mixed load models at each bus are assumed and study is carried out with bus voltage and line power capacity limits for different types of DG using incremental power flow and exhaustive search method as deterministic approach. This analysis shows that mixed load model, types of DG, and power factor of DG have significant impact on size and location of DG.
\end{abstract}

Keywords: Distributed generation, distribution system, distributed generation planning.

DOI: http://dx.doi.org/10.4314/ijest.v4i1.13S

\section{Introduction}

Distributed generation (DG), unlike traditional generation, aims to generate part of required electrical energy on small scale closer to the places of consumption and interchanges the electrical power with the network. It represents a change in the paradigm of electrical energy generation. Distributed generation, also termed as embedded generation or dispersed generation or decentralized generation, is defined as small electric power source that can be connected to a distribution network by a distribution company (DISCO) at any node or by customer at the customer side of the meter (Ackermann et al, 2001). The emergence of new technological alternatives allows the DG technologies in distribution network to achieve immense technical, economical and environmental benefits (Chiradejaand et al, 2004; El-Khattam and Salama, 2004; Pepermans et al, 2005). These benefits could be maximized by proper planning i.e. placement of DGs at optimum locations with optimum size and suitable type under certain constraints for benefits.

The most important factors associated with practical situations are discussed as follows. The load throughout the year is not constant instead it varies with seasonal day and night. The load models to be adopted to represent such kind of loads are described in ( IEEE Task Force, 1993; Qian et al, 2011). In practice, the load at every bus may be the mix kind of load i.e. composition of industrial, residential, and commercial loads. To represent such kind of load, mix load model may be adopted for proper distributed generation planning (DGP) (Qian et al, 2011). The different types of DG have been considered with analytical expression to determine optimal power factor for minimum loss, but without considering load models, in (Hung et al, 2010). In (Dent et al, 2010) the network capacity analysis has been performed using optimal power flow with voltage step constraints for three power factors of DG (0.95 lagging, unity, and 0.95 leading) but without considering the load models, and different types of DG. Thus seasonal load models, mixed seasonal load models, types of DG, and power factor of DG are the influencing factors which must be considered to ensure proper DGP.

In (Qian et al, 2011;Gozel et al,2005; Singh et al, 2007;Singh et al, 2009), different kinds of load models have been considered but the mixed load model at every bus has not been considered except in (Qian et al ). The variable loads, but without load model, has been considered in (Zhu et al, 2006; Ochoa et al, 2008; Atwa et al, 2010). The DGP problem was solved by adopting the type of DG which can supply both active and reactive power, but without load models in ( El-Khattam et al,2005; 
Vovos et al, 2005; Vovos et al, 2005; Harrison et al, 2008; Algarni et al, 2009; Kumar et al, 2010; Kumar et al, 2010) . The literature review (payasi et al, 2011) manifest that comparative study of different types of DGs with seasonal mixed load models is required to be performed for better DG planning.

In this paper, 38 bus test system and data from (Singh et al, 2007) is adopted and DGP is performed using incremental power flow and exhaustive search method with summer day, summer night, winter day, and winter night load models which include industrial, residential, and commercial load models at every bus in certain proportion. Different types of DG with bus voltage limits and line power capacity limit, and seasonal mixed load models are considered for investigation. The results are tabulated and analyzed for: 1) minimum power intake; and 2) minimum real power loss with different types of DG and seasonal mixed load models.

This paper is structured as follows: Section 2 describes the types of DG. Section 3 describes the load models and test cases considered for study. Section 4 describes the methodology adopted. Section 5 presents the simulation result. The last section 6 presents the conclusion of the study.

\section{Types of Distributed Generation}

The different types of traditional and nontraditional DGs are classified and described in (El-Khattam and Salama, 2004) from the constructional, technological, size, and power time duration pint of view. The DGs may also be grouped into four major types based on terminal characteristics in terms of real and reactive power delivering capability as described in (Hung et al, 2010). In this paper, the four major types are considered for comparative studies which are described as follows:

Type1: This type DG is capable of delivering only active power such as photovoltaic, micro turbines, fuel cells, which are integrated to the main grid with the help of converters/inverters. However, according to current situation and grid codes the photovoltaic can and in sometimes are required to provide reactive power as well.

Type2: DG capable of delivering both active and reactive power. DG units based on synchronous machines (cogeneration, gas turbine, etc.) come under this type

Type3: DG capable of delivering only reactive power. Synchronous compensators such as gas turbines are the example of this type and operate at zero power factors.

Type4: DG capable of delivering active power but consuming reactive power. Mainly induction generators, which are used in wind farms, come under this category. However, doubly fed induction generator (DFIG) systems may consume or produce reactive power i.e. operates similar to synchronous generator.

In this paper, the analysis of T1, T2, T3, and T4 for optimal size and location is done on the basis of terminal characteristic of basic DGs in terms of their power delivering capability.

\section{Load models and Test Cases}

To quantify the effect of different types of DG, on DGP, for different load scenario i.e. summer day, summer night, winter day, and winter night loads, a 38 bus distribution system is adopted (Singh et al, 2007). In this paper, the line impedances, load data and the line power limits are expressed in p.u. at the base voltage of $12.66 \mathrm{kV}$ and base MVA of 10 MVA ( Singh et al, 2007) as depicted in Table 5 ( Appendix A). The network is also shown in Figure 9 (Appendix A). In conventional load flow analysis, the active and reactive power loads are assumed as constant power load whereas, in practice, the loads may be voltage dependent i.e. industrial, residential, and commercial loads which may be represented by models as described in (IEEE Task Force, 1993). The voltage dependent load model is a static load model that represents the power relationship to voltage as an exponential equation, and represented in following form.

$$
\begin{gathered}
P_{i}=P_{0 i}\left(\left|V_{i}\right| /\left|V_{0 i}\right|\right)^{\alpha} \\
Q_{i}=Q_{0 i}\left(\left|V_{i}\right| /\left|V_{0 i}\right|\right)^{\beta}
\end{gathered}
$$

where, $P_{i}, Q_{i}, P_{0 \mathrm{i}}, Q_{0 \mathrm{i}}, V_{i}$, and $V_{0 i}$ are in per unit. Above equations (1) and (2) neglect the frequency dependence of distribution system load, due to the fact that it is pan-system phenomenon which can't be controlled locally and remain same for whole of the system. In practice, the load on each bus may be the composition of industrial, residential, and commercial which may vary with seasonal day and night. Therefore, in this paper the seasonal mixed load model at each bus is considered as described in (Qian et $a l, 2011)$ and represented in following form. 


$$
\begin{aligned}
& P_{i}=w_{i p i} \cdot P_{0 i}\left(\left|V_{i}\right| /\left|V_{0 i}\right|\right)^{\alpha_{i}}+w_{r p i} \cdot P_{0 i}\left(\left|V_{i}\right| /\left|V_{0 i}\right|\right)^{\alpha_{r}}+w_{c p i} \cdot P_{0 i}\left(\left|V_{i}\right| /\left|V_{0 i}\right|\right)^{\alpha_{c}} \\
& Q_{i}=w_{i q i} \cdot Q_{0 i}\left(\left|V_{i}\right| /\left|V_{0 i}\right|\right)^{\beta_{i}}+w_{r q i} \cdot Q_{0 i}\left(\left|V_{i}\right| /\left|V_{0 i}\right|\right)^{\beta_{r}}+w_{c q i} \cdot Q_{0 i}\left(\left|V_{i}\right| /\left|V_{0 i}\right|\right)^{\beta_{c}}
\end{aligned}
$$

where, $\quad \alpha_{\mathrm{i}}$ and $\beta_{\mathrm{i}}$ are active and reactive exponents for industrial load model

$\alpha_{\mathrm{r}}$ and $\beta_{\mathrm{r}}$ are active and reactive exponents for residential load model

$\alpha_{c}$ and $\beta_{c}$ are active and reactive exponents for commercial load model

$w_{i p i}, w_{r p i}$, and $w_{c p i}$ are the relevant factors for active industrial, residential, and commercial Load models at bus $i$.

$w_{i q i}, w_{r q i}$, and $w_{c q i}$ are the relevant factors for reactive industrial, residential, and commercial Load models at bus $i$.

The following condition must be satisfied for all buses except buses without load (BWL) ( Bus 1 is slack bus and buses 34 to 38 are not having load).

$$
\begin{gathered}
w_{i p i}+w_{r p i}+w_{s p i}=1, \text { for } i=1 \text { to } N_{B}, \text { but } i \neq B W L \\
w_{i q i}+w_{r q i}+w_{c q i}=1, \text { for } i=1 \text { to } N_{B}, \text { but } i \neq B W L
\end{gathered}
$$

The values for exponents of voltage for active and reactive component of summer day, summer night, winter day, and winter night load models are given in Table 1 (Qian et al, 2011). The relevant factor of each load model at each bus is (hypothetically generated) given in Table 2. In this study it is assumed that $w_{i p}=w_{i q}, w_{r p}=w_{r q}$, and $w_{c p}=w_{c q}$.

The study is performed considering the situations of load, may be, in practice as follows: 1) each bus having mix of industrial, residential, and commercial load in certain proportion; 2) Loads vary with seasonal day and night. Apart from these situations, T1, T2, T3 and T4 are considered for comparative study. A 38 bus system is assumed to be supplying power to mix of industrial, residential, and commercial load without violating bus voltage and line capacity limits. The following test cases are developed for optimal size and location of DG for constant and seasonal mixed load models for two objectives: 1) Real power loss $\left(P_{L}\right)$ minimization; and 2) Apparent power intake $\left(S_{\text {int }}\right)$ minimization.

- Type $1 \mathrm{DG}$

- Type 2 DG

- Type 3 DG

- Type 4 DG

The parameters considered for study are as follows:

a) Number of voltage limit violations (NVLV)

b) Number of line limit violations(NLCLV)

c) Apparent power intake $\left(S_{i n t}\right)$, real power intake $\left(P_{\text {int }}\right)$, and reactive power intake $\left(Q_{\text {int }}\right)$ at bus 1

d) Real and reactive power loss $\left(P_{L}\right.$ and $\left.Q_{L}\right)$

e) Apparent system power requirement $\left(S_{\text {sys }}\right)$

f) Indices (PLI, QLI, VPI, and LCI)

Table 1. Exponent values for load models

\begin{tabular}{|c|c|c|c|c|c|c|c|}
\hline \multirow{2}{*}{ Load duration } & \multicolumn{6}{c|}{ Load models } \\
\cline { 3 - 8 } & \multicolumn{2}{|c|}{ Industrial } & \multicolumn{2}{c|}{ Residential } & \multicolumn{2}{c|}{ Commercial } \\
\cline { 3 - 8 } & $\alpha_{\mathrm{i}}$ & $\beta_{\mathrm{i}}$ & $\alpha_{\mathrm{r}}$ & $\beta_{\mathrm{r}}$ & $\alpha_{\mathrm{c}}$ & $\beta_{\mathrm{c}}$ \\
\hline \multirow{3}{*}{ Summer } & Day & 0.18 & 6.00 & 0.72 & 2.96 & 1.25 & 3.50 \\
\cline { 2 - 8 } & Night & 0.18 & 6.00 & 0.92 & 4.04 & 0.99 & 3.95 \\
\hline \multirow{3}{*}{ Winter } & Day & 0.18 & 6.00 & 1.04 & 4.19 & 1.50 & 3.15 \\
\cline { 2 - 8 } & Night & 0.18 & 6.00 & 1.30 & 4.38 & 1.51 & 3.40 \\
\hline
\end{tabular}


Table 2. Values of relevant factors of load models for buses with load.

\begin{tabular}{|c|c|c|c|}
\hline Bus no. & $w_{\text {ip }}\left(=w_{\text {iq }}\right)$ & $w_{r p}\left(=w_{r q}\right)$ & $w_{c p}\left(=w_{c q}\right)$ \\
\hline 1(GSP) & 0.0 & 0.0 & 0.0 \\
\hline 2 & 0.2000 & 0.6000 & 0.2000 \\
\hline 3 & 0.1500 & 0.6500 & 0.2000 \\
\hline 4 & 0.2000 & 0.5000 & 0.3000 \\
\hline 5 & 0.1100 & 0.3400 & 0.5500 \\
\hline 6 & 0.1000 & 0.3500 & 0.5500 \\
\hline 7 & 0.3000 & 0.5000 & 0.2000 \\
\hline 8 & 0.3000 & 0.5000 & 0.2000 \\
\hline 9 & 0.0800 & 0.2000 & 0.7200 \\
\hline 10 & 0.0800 & 0.2000 & 0.7200 \\
\hline 11 & 0.1200 & 0.2000 & 0.6800 \\
\hline 12 & 0.2500 & 0.3000 & 0.4500 \\
\hline 13 & 0.2500 & 0.3500 & 0.4000 \\
\hline 14 & 0.2000 & 0.3000 & 0.5000 \\
\hline 15 & 0.0500 & 0.3000 & 0.6500 \\
\hline 16 & 0.0800 & 0.2000 & 0.7200 \\
\hline 17 & 0.0800 & 0.2000 & 0.7200 \\
\hline 18 & 0.3000 & 0.4000 & 0.3000 \\
\hline 19 & 0.3000 & 0.4000 & 0.3000 \\
\hline 20 & 0.3000 & 0.4000 & 0.3000 \\
\hline 21 & 0.3000 & 0.4000 & 0.3000 \\
\hline 22 & 0.3000 & 0.4000 & 0.3000 \\
\hline 23 & 0.3500 & 0.4500 & 0.2000 \\
\hline 24 & 0.2000 & 0.6500 & 0.1500 \\
\hline 25 & 0.2000 & 0.6500 & 0.1500 \\
\hline 26 & 0.1000 & 0.2500 & 0.6500 \\
\hline 27 & 0.1000 & 0.2500 & 0.6500 \\
\hline 28 & 0.1000 & 0.3000 & 0.6000 \\
\hline 29 & 0.2500 & 0.3500 & 0.4000 \\
\hline 30 & 0.5000 & 0.3000 & 0.2000 \\
\hline 31 & 0.2500 & 0.3500 & 0.4000 \\
\hline 32 & 0.3000 & 0.5000 & 0.2000 \\
\hline 33 & 0.2500 & 0.3000 & 0.4500 \\
\hline 34 & 0.0000 & 0.0000 & 0.0000 \\
\hline 35 & 0.0000 & 0.0000 & 0.0000 \\
\hline 36 & 0.0000 & 0.0000 & 0.0000 \\
\hline 37 & 0.0000 & 0.0000 & 0.0000 \\
\hline 38 & 0.0000 & 0.0000 & 0.0000 \\
\hline
\end{tabular}

\section{Proposed Methodology}

\subsection{Problem Formulation}

The formulation of DGP problem is proposed on the basis of two objective functions 1) real power loss ; 2) Apparent power intake

Minimization of real power loss: The objective function is total real power loss $\left(P_{L}\right)$ in the system. The $P_{L}$ in the system is represented by

$$
P_{L}=\sum_{i, j \in N_{L}} \frac{P_{i j}^{2}+Q_{i j}^{2}}{\left|V_{i}\right|^{2}} r_{i j}
$$

The $P_{L}$ is function of all system bus voltage $\left(V_{i}\right)$, line resistances $\left(r_{i, j}\right), \alpha$, and $\beta$. The total losses mainly depend on voltage profile. Minimization of total power intake at substation: The objective function is apparent power intake $\left(S_{\text {int }}\right)$ at main substation. The $P_{\text {int }}$ is the sum of $P_{D}$ and $P_{L}$, and represented by

$$
P_{\text {int }}=P_{1}\left(V, P_{0}, Q_{0}, \alpha, \beta\right)=P_{D}+P_{L}=\sum_{i=1}^{N_{B}} P_{0 i}\left(\left|V_{i}\right| /\left|V_{0 i}\right|\right)^{\alpha}+P_{L}
$$

Similarly, the $Q_{i n t}$ is the sum of $Q_{D}$ and $Q_{L}$, and represented by

$$
Q_{\text {int }}=Q_{1}\left(V, P_{0}, Q_{0}, \alpha, \beta\right)=Q_{D}+Q_{L}=\sum_{i=1}^{N_{B}} Q_{0 i}\left(\left|V_{i}\right| /\left|V_{0 i}\right|\right)^{\beta}+Q_{L}
$$


Apparent power intake at main substation is expressed as

$$
S_{\text {int }}=\left[\left(P_{\text {int }}\right)^{2}+\left(Q_{\text {int }}\right)^{2}\right]^{1 / 2}
$$

And Apparent power requirement for distribution system is expressed as:

$$
S_{\text {sys }}=\left[\left(P_{\text {int }}+P_{D G}\right)^{2}+\left(Q_{\text {int }}+Q_{D G}\right)^{2}\right]^{1 / 2}
$$

where, based on terminal characteristic

$$
\begin{aligned}
& Q_{D G}=0.0 \text { for Type } 1 \mathrm{DG} \\
& P_{D G}=0.0 \text { for Type } 3 \mathrm{DG} \\
& Q_{D G}=- \text { ve for Type } 4 \mathrm{DG}
\end{aligned}
$$

It is observed that for a distribution system

$$
\begin{aligned}
& \sum_{i=1}^{N_{B}} P_{0 i}\left(\left|V_{i}\right| /\left|V_{0 i}\right|\right)^{\alpha}>>P_{L} \quad \text { and } \\
& \sum_{i=1}^{N_{B}} Q_{0 i}\left(\left|V_{i}\right| /\left|V_{0 i}\right|\right)^{\beta}>>Q_{L}
\end{aligned}
$$

Thus the $P_{\text {int }}$ and $Q_{\text {int }}$ in (8)and (9) respectively are largely decided by the load exponents, $\alpha$, and $\beta$, not by $P_{L}$ and $Q_{L}$.

The above objectives are subject to the following set of power flows, voltage limits, line power capacity limit, and DG size limit.

$$
\begin{gathered}
P_{i}=\sum_{j=1}^{N_{B}}\left|V_{i}\right|\left|V_{j}\right|\left[G_{i j} \cos \left(\delta_{i}-\delta_{j}\right)+B_{i j} \sin \left(\delta_{i}-\delta_{j}\right)\right], \text { for } i=1 \text { to } N_{B} \\
Q_{i}=\sum_{j=1}^{N_{B}}\left|V_{i}\right|\left|V_{j}\right|\left[G_{i j} \sin \left(\delta_{i}-\delta_{j}\right)-B_{i j} \cos \left(\delta_{i}-\delta_{j}\right)\right], \text { for } i=1 \text { to } N_{B} \\
P_{i, j}=\left|V_{i}\right|^{2} G_{i j}-\left|V_{i}\right|\left|V_{j}\right|\left[G_{i j} \cos \theta_{i j}-B_{i j} \sin \theta_{i j}\right], \text { for } i j \in N_{L} \\
Q_{i, j}=-\left|V_{i}\right|^{2} B_{i j}-\left|V_{i}\right|\left|V_{j}\right|\left[G_{i j} \sin \theta_{i j}+B_{i j} \cos \theta_{i j}\right], \text { for } i j \in N_{L} \\
V_{\min } \leq\left|V_{i}\right| \leq V_{\max }, \quad \text { for } i=1 \text { to } N_{B} \\
S_{i, j} \leq C S_{i, j}^{\max }, \quad \text { for } i j \in N_{L} \\
P_{D G} \leq P_{\text {int }}
\end{gathered}
$$

In this paper voltage limits and line power capacity limit are as follows:

$$
\begin{aligned}
& V_{\min }=0.95 \text { p.u. } \\
& V_{\max }=1.03 \text { p.u. } \\
& C S_{i, j}^{\max }, \quad \text { for } i, j \in N_{L} \text {; Power capacity limits are in Table 5(Appendix A) }
\end{aligned}
$$

\subsection{Indices to quantify the benefits of $D G$}

The indices to quantify the benefits of DG are defined as follows (Singh et al, 2007).

Real Power Loss Index (PLI): The real power loss index is defined as :

$$
P L I=\frac{P_{L W D G}}{P_{L W O D G}} \times 100
$$

The lower values of this index indicate better benefits in terms of real power loss reduction accrued due to DG location and size. Reactive Power Loss Index (QLI): The reactive power loss index is defined as:

$$
Q L I=\frac{Q_{L W D G}}{Q_{L W O D G}} \times 100
$$


The lower values of this index indicate better benefits in terms of reactive power loss reduction accrued due to DG location and size.

Voltage Profile Index (VPI): It is related to the maximum voltage drop between each node and root node. The lower values of this index indicate better performance of network. The VPI can be defined as:

$$
V P I=\max \left(\frac{\left|V_{1}\right|-\left|V_{i}\right|}{\left|V_{1}\right|}\right) \times 100, \quad \text { for } i=2 \text { to } N_{B}
$$

Line Capacity Index (LCI): The power flows may diminish in some sections of the network and released more capacity with the power supplied near to the load. This index provides important information about the level of power flows/currents through the network regarding maximum capacity of distribution lines. Lower values of this index indicate more capacity available. This is defined as:

$$
L C I=\max \left(\frac{\left|\mathrm{S}_{\mathrm{i}, \mathrm{j}}\right|}{\left|\mathrm{CS}_{\mathrm{i}, \mathrm{j}}\right|}\right) \times 100, \text { for } i, j=1 \text { to } N_{L}
$$

\subsection{Computational Procedure}

In this paper, T1, T2, T3, and T4 are considered for comparative analysis with two objectives: 1) $P_{L}$ minimization; and 2) $S_{\text {int }}$ minimization. The data base, using incremental power flow method, for the 38-bus distribution system (Singh et al, 2007) is obtained for the cases: i) without DG; and ii) with DG for various types of DG and load models. Then using exhaustive search method (given in Appendix B), DG size and location along with values of other relevant quantities are determined for both objectives. The size of DGs are considered in practical range decided as equal to or less than power intake at main substation (bus 1) as power is not intended to flow to grid. The step size of power of DG is taken as 0.005 p.u. and the step size of power factor is taken as 0.01 . The range of power factor is taken between 0.99 to 0.8 leading for T2 and 0.99 to 0.8 lagging for T4. The quantities evaluated with incremental values of DG at each node are $P_{L}, Q_{L}, S_{i n t}, P_{i n t}, Q_{i n t}, S_{s y s}, N V L V, N L C L V, P L I, Q L I, V P I, L C I, V_{i}$, and $S_{i j}$. The steps of the algorithm, for making the data base, are as follows:

Step 1 : Read of load data, line data, number of buses, DG power increment $\left(\Delta\left|S_{D G}\right|\right), \alpha$ and $\beta$ for all load models, voltage limits, and $\mathrm{DG}$ power factor decrement $\left(\triangle P F_{D G}\right)$ for typ2 and type $4 \mathrm{DG}$.

Step 2 : Select one of the load models (mixed and constant power load models) by selecting exponent values, $\alpha$ and $\beta$.

Step 3 : Run power flow program without $D G$ and save the required quantities.

Step 4 : Select one of types of DG.

Step 5 : Decrement of power factor by $\Delta \mathrm{PF}_{\mathrm{DG}}$ from 0.99 leading for Type2, from 0.99 lagging for Type $4 \mathrm{DG}$ and skip this step for Type 1 and Type 3 DGs.

Step 6 : Select one of the buses.

Step 7 : Increment of DG value by $\Delta S_{D G}$.

Step 8 : Run power flow program and save the required quantities.

Step 9 : Go to step 7 till DG value reached the set value $\left(P_{D G} \leq P_{\text {int }}\right)$.

Step 10: Go to step 6 to select next bus till all the buses are considered.

Step 11: Go to step 5 for type 2 and type $4 \mathrm{DG}$ till $\mathrm{PF}_{\mathrm{DG}}$ is 0.8 and skip this step for type 1 and type $3 \mathrm{DG}$.

Step 12: Go to step 4 to select other type of DG.

Step 13: Go to step 2 till all the mixed load models are selected.

Step 14: The database obtained in terms of DG_bus, $P_{D G}, Q_{D G}, P_{L}, Q_{L}, S_{i n t}, P_{\text {int }}, Q_{\text {int }}, S_{\text {sys }}, N V L V, N L C L V, P L I, Q L I, V P I, L C I$, $V_{i}$, and $S_{i j}$ are used to obtain value of quantities (with zero value of NVLV, NLCLV) corresponding to minimum $P_{L}$, and minimum $S_{\text {int }}$ as depicted in Table III, and IV using exhaustive search method (given in Appendix B).

\section{Simulation Results and Discussion}

In this section, the summary of simulation results obtained for various test cases is presented. The quantities $P_{D G}, Q_{D G}, P F_{D G}$, $S_{\text {int }}, P_{\text {int }}, Q_{i n t}, S_{\text {sys }}, P_{L}, Q_{L}$, corresponding to minimum $P_{L}$ and minimum $S_{\text {int }}$ are presented in Table 3 and 4 respectively. The indices corresponding to minimum $P_{L}$ (for economical operation) and minimum $S_{\text {int }}$ (to defer system upgrade) configuration are depicted from Figure 1 to 8 . The analysis is presented on the basis of results depicted in Table 3 and 4 for various seasonal mixed load models as well as constant power load model and various major types of DG as follows: 
Table 3. Real power loss minimization with various load models and DG types

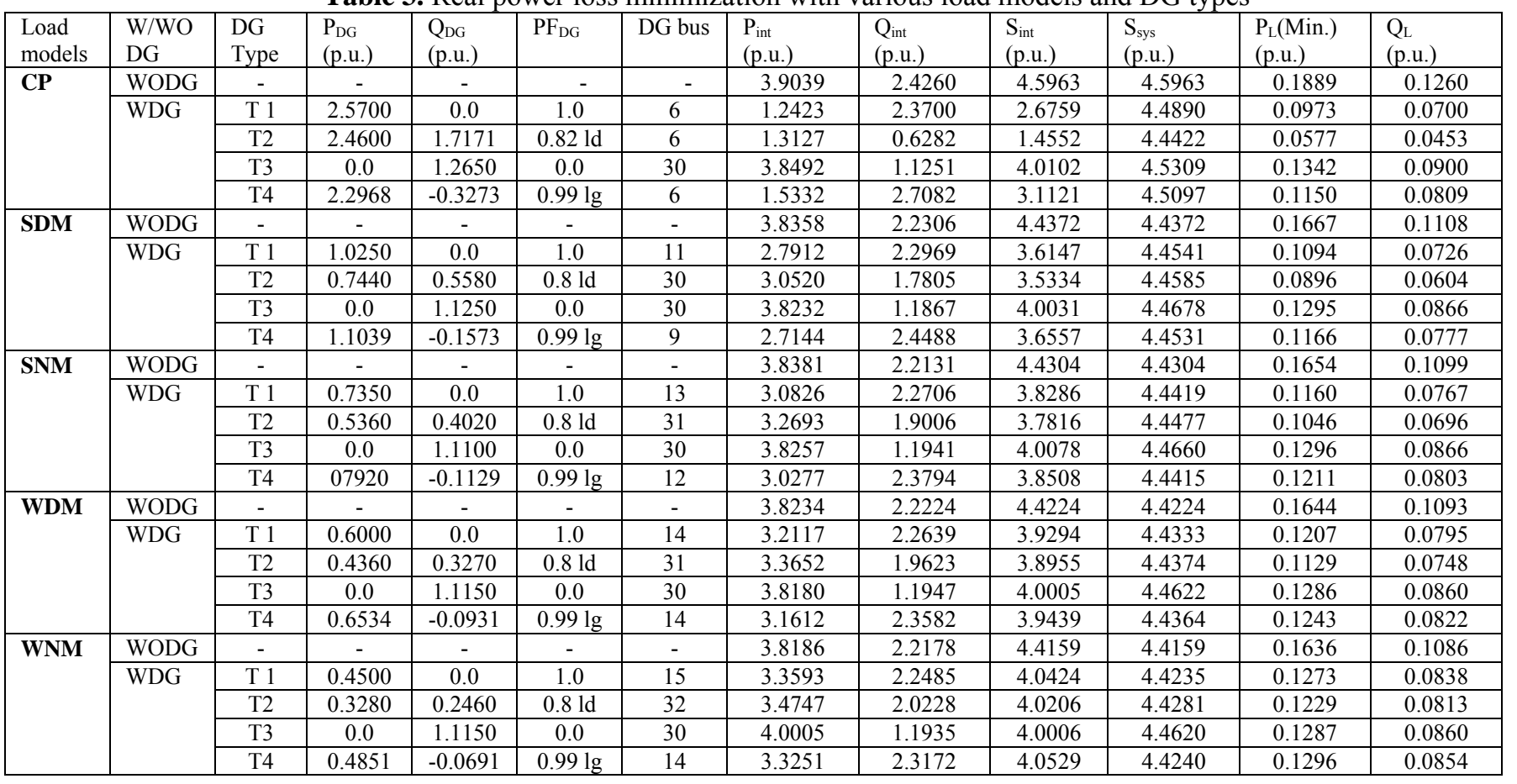

Table 4. Power intake minimization with various load models and DG types

\begin{tabular}{|c|c|c|c|c|c|c|c|c|c|c|c|c|}
\hline $\begin{array}{c}\text { Load } \\
\text { models }\end{array}$ & $\begin{array}{c}\text { W/WO } \\
\text { DG }\end{array}$ & $\begin{array}{l}\text { DG } \\
\text { Type }\end{array}$ & $\begin{array}{c}\mathrm{P}_{\mathrm{DG}} \\
\text { (p.u.) }\end{array}$ & $\begin{array}{c}\mathrm{Q}_{\mathrm{DG}} \\
\text { (p.u.) }\end{array}$ & $\mathrm{PF}_{\mathrm{DG}}$ & DG bus & $\begin{array}{c}P_{\text {int }} \\
\text { (p.u.) }\end{array}$ & $\begin{array}{c}\mathrm{Q}_{\text {int }} \\
\text { (p.u.) }\end{array}$ & $\begin{array}{c}\mathrm{S}_{\text {int }} \\
\text { (p.u.) }\end{array}$ & $\begin{array}{c}\mathrm{S}_{\text {sys }} \\
\text { (p.u.) }\end{array}$ & $\begin{array}{c}\mathrm{P}_{\mathrm{L}} \\
\text { (p.u.) }\end{array}$ & $\begin{array}{c}\mathrm{Q}_{\mathrm{L}} \\
\text { (p.u.) }\end{array}$ \\
\hline \multirow{5}{*}{ CP } & WODG & - & - & - & - & - & 3.9039 & 2.4260 & 4.5963 & 4.5963 & 0.1889 & 0.1260 \\
\hline & \multirow{4}{*}{ WDG } & T1 & 3.6050 & 0.0 & 1 & 6 & 0.2210 & 2.3799 & 2.3902 & 4.5058 & 0.1110 & 0.0799 \\
\hline & & T 2 & 3.4765 & 2.1545 & $0.85 \mathrm{ld}$ & 3 & 0.3632 & 0.2376 & 0.4341 & 4.5240 & 0.1247 & 0.0922 \\
\hline & & $\mathrm{T} 3$ & 0.0 & 2.3450 & 0.0 & 6 & 3.8635 & 0.0563 & 3.8639 & 4.5489 & 0.1485 & 0.1013 \\
\hline & & $\mathrm{T} 4$ & 3.3660 & -0.4796 & $0.99 \mathrm{lg}$ & 6 & 0.4795 & 2.8716 & 2.9113 & 4.5287 & 0.1305 & 0.0920 \\
\hline \multirow{5}{*}{ SDM } & WODG & - & - & - & - & - & 3.8358 & 2.2306 & 4.4372 & 4.4372 & 0.1667 & 0.1108 \\
\hline & \multirow{4}{*}{ WDG } & T 1 & 3.825 & 0.0 & 1.0 & 2 & 0.0092 & 2.2446 & 2.2446 & 4.4428 & 0.1592 & 0.1070 \\
\hline & & T 2 & 3.8236 & 2.1670 & $0.871 d$ & 2 & 0.0096 & 0.0814 & 0.0819 & 4.4440 & 0.1567 & 0.1057 \\
\hline & & T3 & 0.0 & 2.2250 & 0.0 & 2 & 3.8350 & 0.0096 & 3.8349 & 4.4385 & 0.1641 & 0.1095 \\
\hline & & T4 & 3.4304 & -0.4888 & $0.991 \mathrm{~g}$ & 2 & 0.4041 & 2.7310 & 2.7608 & 4.4419 & 0.1605 & 0.1077 \\
\hline \multirow{5}{*}{ SNM } & WODG & - & - & - & - & - & 3.8381 & 2.2131 & 4.4304 & 4.4304 & 0.1654 & 0.1099 \\
\hline & \multirow{4}{*}{ WDG } & T1 & 3.8250 & 0.0 & 1.0 & 2 & 0.0116 & 2.2294 & 2.2294 & 4.4373 & 0.1581 & 0.1063 \\
\hline & & T2 & 3.5862 & 2.1279 & $0.861 d$ & 2 & 0.2491 & 0.1047 & 0.2702 & 4.4378 & 0.1556 & 0.1050 \\
\hline & & T3 & 0.0 & 2.2100 & 0.0 & 2 & 3.8373 & 0.0077 & 3.8373 & 4.4321 & 0.1630 & 0.1087 \\
\hline & & $\mathrm{T} 4$ & 3.4353 & -0.4895 & $0.991 \mathrm{~g}$ & 2 & 0.4016 & 2.7162 & 2.7457 & 4.4362 & 0.1594 & 0.1069 \\
\hline \multirow{5}{*}{ WDM } & WODG & - & - & - & - & - & 3.8234 & 2.2224 & 4.4224 & 4.4224 & 0.1644 & 0.1093 \\
\hline & \multirow{4}{*}{ WDG } & T1 & 3.8100 & 0.0 & 1.0 & 2 & 0.0136 & 2.2380 & 2.2381 & 4.4304 & 0.1572 & 0.1057 \\
\hline & & T 2 & 2.8985 & 1.7963 & $0.85 \mathrm{ld}$ & 2 & 0.9229 & 0.4406 & 1.0227 & 4.4280 & 0.1551 & 0.1045 \\
\hline & & T3 & 0.0 & 2.2200 & 0.0 & 2 & 3.8231 & 0.0068 & 3.8231 & 4.4244 & 0.1620 & 0.1080 \\
\hline & & T4 & 3.4205 & -0.4874 & $0.991 \mathrm{~g}$ & 2 & 0.4032 & 2.7228 & 2.7525 & 4.4291 & 0.1585 & 0.1063 \\
\hline \multirow{5}{*}{ WNM } & WODG & - & - & - & - & - & 3.8186 & 2.2178 & 4.4159 & 4.4159 & 0.1636 & 0.1086 \\
\hline & \multirow{4}{*}{ WDG } & T 1 & 2.8650 & 0.0 & 1.0 & 2 & 0.9530 & 2.2292 & 2.4244 & 4.4211 & 0.1567 & 0.1052 \\
\hline & & T2 & 2.1546 & 1.3917 & $0.841 \mathrm{~d}$ & 2 & 1.6621 & 0.8368 & 1.8608 & 4.4197 & 0.1554 & 0.1045 \\
\hline & & T3 & 0.0 & 2.2150 & 0.0 & 2 & 3.8247 & 0.0101 & 3.8248 & 4.4249 & 0.1621 & 0.1081 \\
\hline & & T4 & 3.0888 & -0.4401 & $0.991 \mathrm{~g}$ & 2 & 0.7301 & 2.6698 & 2.7679 & 4.4222 & 0.1577 & 0.1057 \\
\hline
\end{tabular}

\subsection{Analysis}

Constant power load model (CP): In minimum $P_{L}$ configuration, it is observed that the $P_{L}$ with T2 is 0.0577 p.u. which is less compared to with other types of DGs and without DG. The $P_{D G}$ is 2.4600 p.u., at 0.82 leading power factor, which is less than with T1 and greater than with T4. The $S_{\text {int }}$ with T2 is 1.4552 p.u. which is less than with other type of DGs and without DG. The location of T1, T2, and T4 is at bus 6 whereas of T3 is at bus 30 .

In minimum $S_{i n t}$, configuration (to defer substation upgrade), the $S_{i n t}$, with T2 is 0.4341 p.u. which is less than with T1, T3, T4, and without DG. The $P_{D G}$ of T2 is 3.4765 p.u. at 0.85 leading power factor which is less than with T1 and little more than T4. 
The $P_{L}$ with T2 is 0.1247 which is less than with T3 and T4, and greater than with T1. The location of T1, T3, and T4 is bus 6 (away from substation) whereas for T2 is bus 3 (closer to substation to accommodate greater value of DG).

Summer day mix load model (SDM): In minimum $P_{L}$ configuration, the $P_{L}$ and $Q_{L}$ with T2 is 0.0896 p.u. and 0.0604 p.u. respectively whereas with other type of DGs and without DG are more. The value of $P_{D G}$ with T2 is 0.7440 p.u., at 0.8 leading power factor, which is less than with T1 and T4. The location of T1 is 11, T2 and T3 is 30, and T4 is 9,.

In minimum $S_{\text {int }}$ configuration, the location is same (bus 2) for all types of DG. The $S_{\text {int }}$ with T2 is much less (0.0819 p.u.) than with other type of DGs. The $P_{L}$ and $Q_{L}$ with T2 is 0.1567 p.u. and 0.1057 p.u. respectively which are less than without DG and with other type of DGs. The $P_{D G}$ of T2 is 3.8236 p.u.( at $P F_{D G}=0.87 \mathrm{ld}$ ) which is more than that of T1 and T4.

Summer night mixed load model (SNM): In minimum $P_{L}$ configuration, The $P_{L}$ and $Q_{L}$ with T2 is 0.1046 p.u. and 0.0696 p.u. respectively whereas with other DGs and without DG are more. The $P_{D G}$ of T2 is 0.536 p.u., at 0.80 leading power factor, which is less than other type of DGs. The location of T1, T2, T3, and T4 are 13, 31, 30, and 12 respectively.

In minimum $S_{\text {int }}$ configuration, the $S_{\text {int }}$ with T2 is 0.2702 p.u. which is much less than with other type of DGs. The $P_{D G}$ with T2 is 3.5862 p.u., at 0.86 leading power factor, which is less than with T1 and greater than with T4. The $P_{L}$ and $Q_{L}$ with T2 are 0.1556 p.u. and 0.1050 p.u. respectively which are less compared to without DG and with other type of DGs. The location of all type of DGs is same i.e. bus 2, and it is same as for SDM.

Winter day mixed load model (WDM): In minimum $P_{L}$ configuration, the $P_{L}$ and $Q_{L}$ with T2 are 0.1129 p.u. and 0.0748 p.u. respectively which are less than without DG and with other type of DGs. The $P_{D G}$ is 0.436 p.u. , at 0.8 leading power factor, which is less than T1 and T4. The location of T2 and T3 is same as in case of SNM load model i.e. bus 31 and 30 respectively. The location for $\mathrm{T} 1$ and $\mathrm{T} 4$ is bus 14.

In $S_{\text {int }}$ configuration, the $S_{\text {int }}$ with T2 is 1.0227 p.u. which is less than with all other type of DGs. The $P_{L}$ and $Q_{L}$ with T2 are 0.1551 p.u. and 0.1045 p.u. which are less than without DG and with other type of DGs. The $P_{D G}$ of T2 is 2.8985 p.u. , at 0.85 leading power factor, which is less than with T1 and T4. The location of all type of DGs is at bus 2.

Winter night mixed load model (WNM): In minimum $\mathrm{P}_{\mathrm{L}}$ configuration, the $P_{L}$ and $Q_{L}$ with $\mathrm{T} 2$ is 0.1229 p.u. and 0.0813 p.u. which are less compared to without DG as well as with other type of DGs. $P_{D G}$ of T2 is 0.3280 p.u. $\left(\right.$ at $P F_{D G}=0.80$ leading) which is less than with other type of DGs. The location is different for different type of DGs.

In minimum $S_{\text {int }}$, configuration, the $S_{\text {int }}$, with T2 is 1.8608 p.u. which is less than with other type of DGs. The $P_{L}$ and $Q_{L}$ with T2 are 0.1554 p.u. and 0.1045 respectively which are less than without DG as well as with other type of DGs. The $P_{D G}$ of T2 is 2.1546 p.u. , at 0.84 ld power factor, which is less than other type of DGs. The location of all type of DGs is same i.e. bus 2 as in case of other mixed load models.

\subsection{Discussion}

In minimum $P_{L}$ configuration, it is observed that in order to minimize $P_{L}$, the $P_{L}$ is less for all seasonal load models only with T2 compared to other type of DGs. The optimum locations for T2 are at bus 29 for SDM, bus 31 for SNM and WDM, and 32 for WNM load models. The optimum $P_{D G}$ is also with T2 compared to with T1 and T4 in for all load models. The operating range of power factor for $\mathrm{T} 2$ is 0.8 to $0.82 \mathrm{ld}$ to meat reactive power demand.

In case of minimum $S_{\text {int }}$ configuration, in order to minimize the $S_{\text {int }}$ maintaining the line limits, it is suitable to place the DG at that node where maximum line power limit is found, i.e. the line from main substation to the next node i.e. bus 2 . Hence in all mixed load models, the optimum location for minimum $S_{\text {int }}$ comes out to be bus 2 . In this study, optimum location for minimum $S_{\text {int }}$ for all mixed load model with each type of DG has come out as bus 2 because bus 1 is not considered as candidate location. It is also observed that with T2 the $S_{\text {int }}$ as well as $P_{L}$ and $Q_{L}$ is minimum compared to other type of DGs for all the mixed load models. The operating range of power factor with $\mathrm{T} 2$ is $0.85 \mathrm{ld}$ to $0.87 \mathrm{ld}$ to meet the reactive power demand.

In both configurations, it is observed that optimal performance of Type $4 \mathrm{DG}$ is at $0.99 \mathrm{lg}$ (closer to unity). This reveals that such DGs are to be operated on unity power factor if possible or otherwise would impose additional power factor constraints on system. However, in certain case it may not be possible to run on unity power factor such as induction generator. Therefore, they may be represented as having reactive power (fixed or variable) such as DFIG.

For minimum $P_{L}$ and minimum $S_{\text {int }}$ configuration the indices PLI, QLI, VPI, and LCI are depicted from Figure 1 to 4, and Figure 5 to 8 respectively. From the figures it is evident that reduction in $P_{L}$, and $Q_{L}$ with T2 are more, for all load models, compared to T1,T3, and T4 in both configuration.

The voltage profile seems to be improved with all type of DGs for all seasonal load models in both configurations compared to without DG case.

The capacity release for constant load model is more with all type of DGs compared to without DG whereas for seasonal mixed load models the capacity release is less compared to without DG. This reveals that assumption of constant load model may not lead to proper DG planning. Among all type of DGs, T3 depicts more line capacity release for all seasonal load models in both configurations.

Besides, the $S_{s y s}$ with all type of DGs is comparable for all seasonal load models but less than constant load model which also reveals that assumption of constant power load model may not be suitable for proper DGP. 
Indices for minimum $P_{L}$ with various load models:

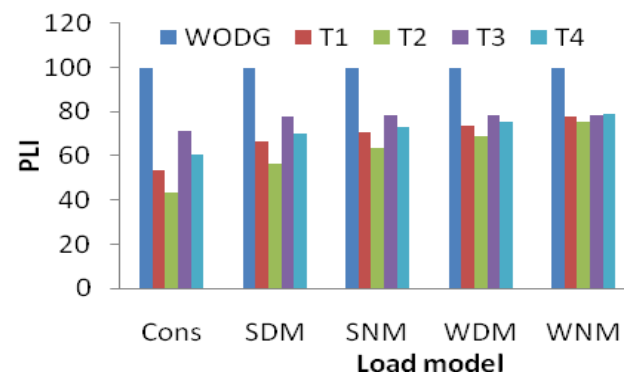

Figure 1. PLI for minimum $P_{L}$

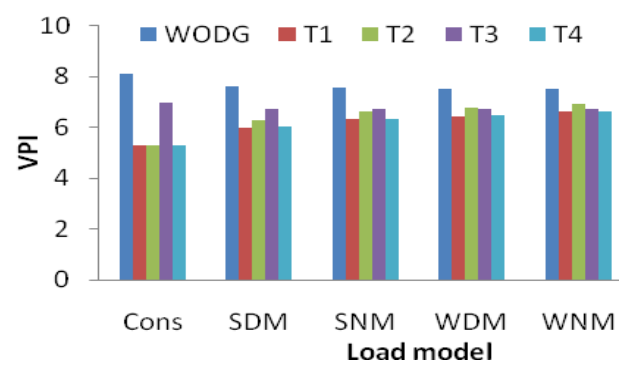

Figure 3. VPI for minimum $P_{L}$

Indices for minimum $S_{\text {int }}$ with various load models:

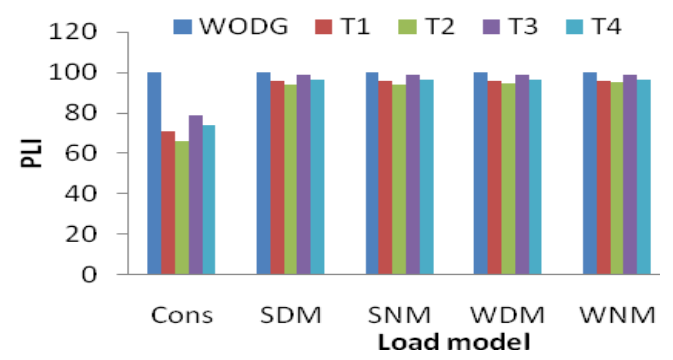

Figure 5. PLI for minimum $S_{\text {int }}$

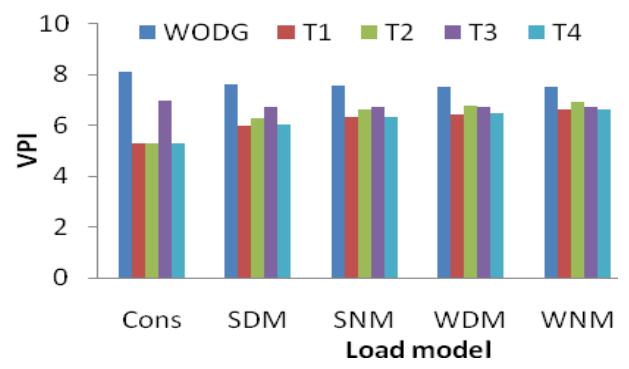

Figure 7. VPI for minimum $S_{\text {int }}$

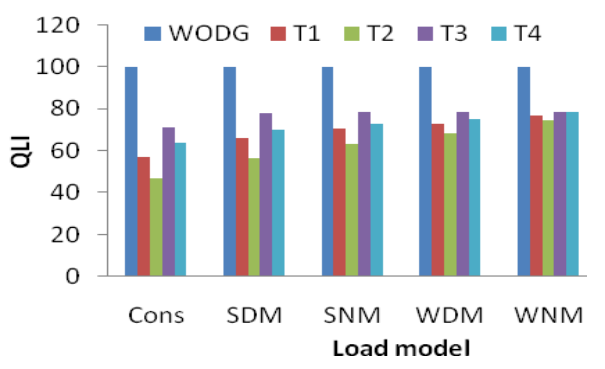

Figure 2. QLI for minimum $P_{L}$

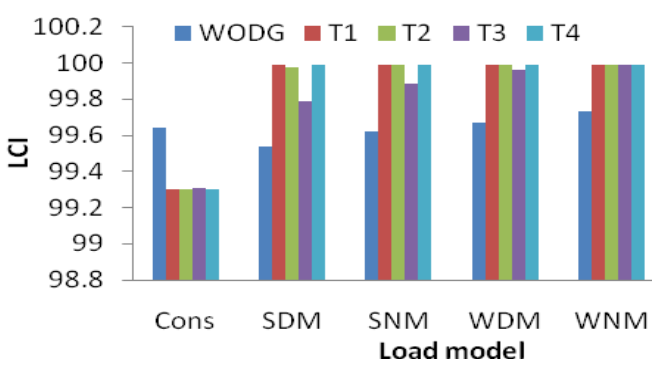

Figure 4. LCI for minimum $P_{L}$

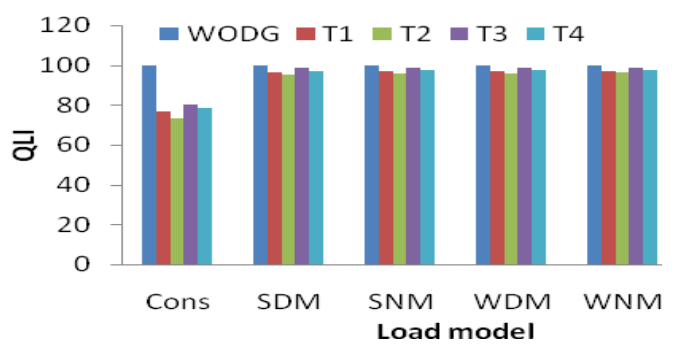

Figure 6. QLI for minimum $S_{i n t}$

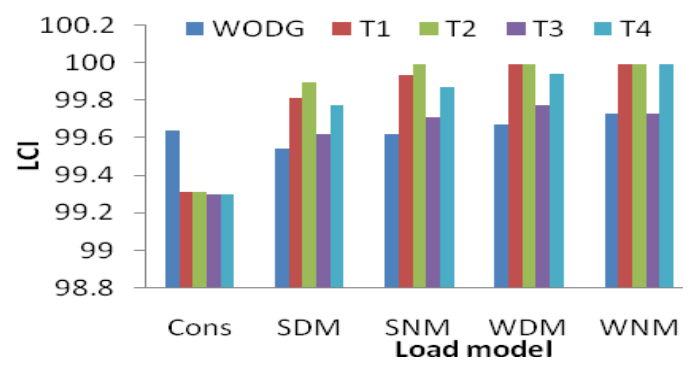

Figure 8. LCI for minimum $S_{\text {int }}$ 


\section{Conclusion}

In this work mixed load model at every bus, DG types based on terminal characteristic, seasonal mixed load models as well as constant power load model have been considered. From analysis it is found that Type 2 DG has significant impact on DG planning compared to other types of DG. It is also investigated that DG planning based on constant power load model is different than the mixed load models which reveals that the assumption of constant power load model may not lead to proper DG planning. Type2 DG, as compared to others, has significant influence on relevant quantities such as : 1) real and reactive power loss reduction; 2) DG size reduction; 3) Power intake reduction.

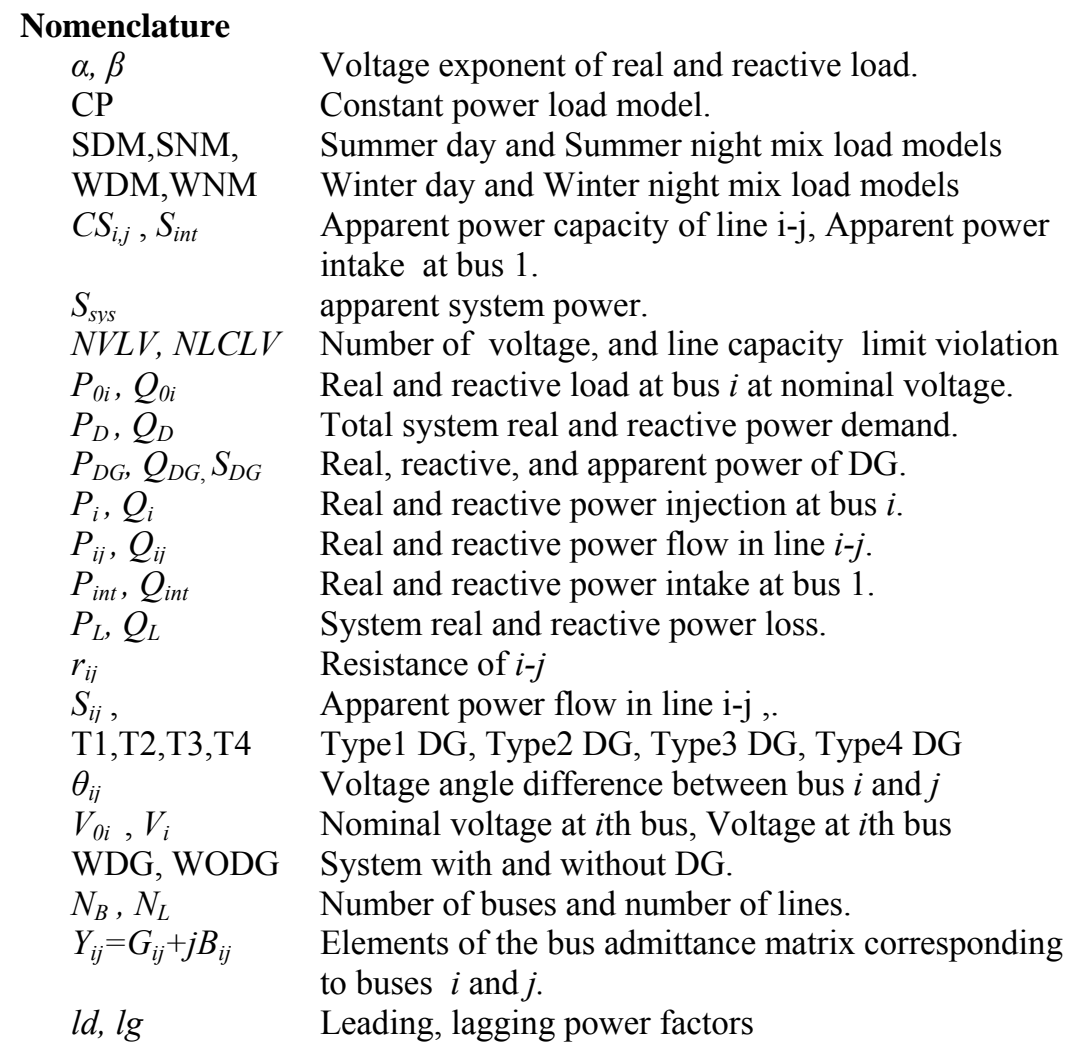

\section{Appendix A}

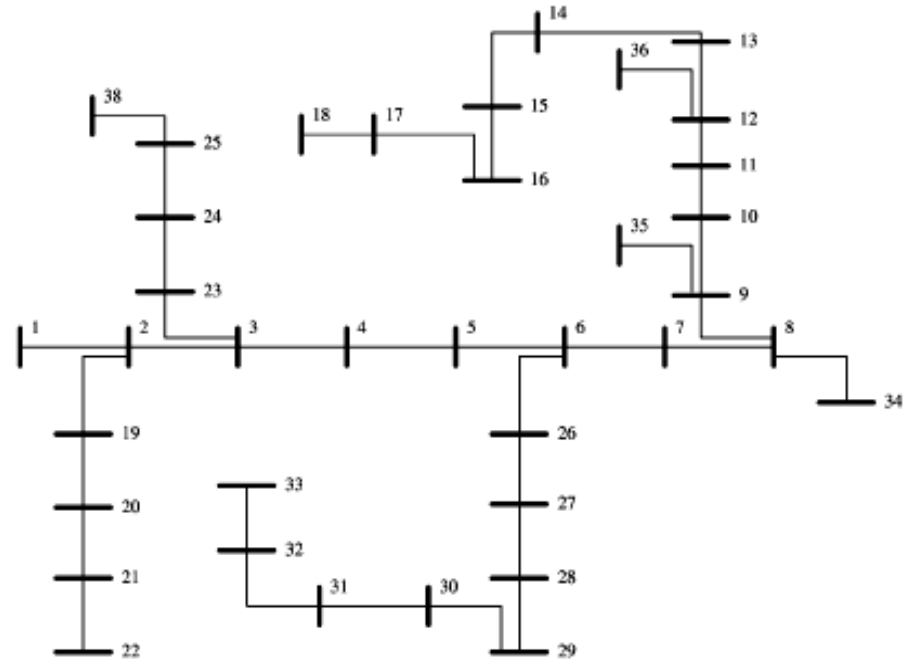

Figure 9. The 38 bus test system ( Singh et al, 2007). 
Table 5. Lines parameter and load data for 38 bus system ( Singh et al, 2007).

\begin{tabular}{|c|c|c|c|c|c|c|c|}
\hline \multirow[t]{2}{*}{$\mathrm{F}$} & \multirow[t]{2}{*}{$\mathrm{T}$} & \multicolumn{2}{|c|}{$\begin{array}{l}\text { Line impedance } \\
\text { (p. u.) }\end{array}$} & \multirow[t]{2}{*}{$\mathrm{L}$} & \multirow[t]{2}{*}{$\mathrm{S}_{\mathrm{L}}$} & \multicolumn{2}{|c|}{$\begin{array}{l}\text { Load on to bus } \\
\text { (p. u.) }\end{array}$} \\
\hline & & $\mathrm{R}$ & $\mathrm{X}$ & & & $\mathrm{P}$ & $\mathrm{Q}$ \\
\hline 1 & 2 & 0.000574 & 0.000293 & 1 & 4.60 & 0.10 & 0.06 \\
\hline 2 & 3 & 0.003070 & 0.001564 & 6 & 4.10 & 0.09 & 0.04 \\
\hline 3 & 4 & 0.002279 & 0.001161 & 11 & 2.90 & 0.12 & 0.08 \\
\hline 4 & 5 & 0.002373 & 0.001209 & 12 & 2.90 & 0.06 & 0.03 \\
\hline 5 & 6 & 0.005100 & 0.004402 & 13 & 2.90 & 0.06 & 0.02 \\
\hline 6 & 7 & 0.001166 & 0.003853 & 22 & 1.50 & 0.20 & 0.10 \\
\hline 7 & 8 & 0.004430 & 0.001464 & 23 & 1.05 & 0.20 & 0.10 \\
\hline 8 & 9 & 0.006413 & 0.004608 & 25 & 1.05 & 0.06 & 0.02 \\
\hline 9 & 10 & 0.006501 & 0.004608 & 27 & 1.05 & 0.06 & 0.02 \\
\hline 10 & 11 & 0.001224 & 0.000405 & 28 & 1.05 & 0.045 & 0.03 \\
\hline 11 & 12 & 0.002331 & 0.000771 & 29 & 1.05 & 0.06 & 0.035 \\
\hline 12 & 13 & 0.009141 & 0.007192 & 31 & 0.50 & 0.06 & 0.035 \\
\hline 13 & 14 & 0.003372 & 0.004439 & 32 & 0.45 & 0.12 & 0.08 \\
\hline 14 & 15 & 0.003680 & 0.003275 & 33 & 0.30 & 0.06 & 0.01 \\
\hline 15 & 16 & 0.004647 & 0.003394 & 34 & 0.25 & 0.06 & 0.02 \\
\hline 16 & 17 & 0.008026 & 0.010716 & 35 & 0.25 & 0.06 & 0.02 \\
\hline 17 & 18 & 0.004538 & 0.003574 & 36 & 0.10 & 0.09 & 0.04 \\
\hline 2 & 19 & 0.001021 & 0.000974 & 2 & 0.50 & 0.09 & 0.04 \\
\hline 19 & 20 & 0.009366 & 0.008440 & 3 & 0.50 & 0.09 & 0.04 \\
\hline 20 & 21 & 0.002550 & 0.002979 & 4 & 0.21 & 0.09 & 0.04 \\
\hline 21 & 22 & 0.004414 & 0.005836 & 5 & 0.11 & 0.09 & 0.04 \\
\hline 3 & 23 & 0.002809 & 0.001920 & 7 & 1.05 & 0.09 & 0.05 \\
\hline 23 & 24 & 0.005592 & 0.004415 & 8 & 1.05 & 0.42 & 0.20 \\
\hline 24 & 25 & 0.005579 & 0.004366 & 9 & 0.50 & 0.42 & 0.20 \\
\hline 6 & 26 & 0.001264 & 0.000644 & 14 & 1.50 & 0.06 & 0.025 \\
\hline 26 & 27 & 0.001770 & 0.000901 & 15 & 1.50 & 0.06 & 0.025 \\
\hline 27 & 28 & 0.006594 & 0.005814 & 16 & 1.50 & 0.06 & 0.02 \\
\hline 28 & 29 & 0.005007 & 0.004362 & 17 & 1.50 & 0.12 & 0.07 \\
\hline 29 & 30 & 0.003160 & 0.001610 & 18 & 1.50 & 0.20 & 0.60 \\
\hline 30 & 31 & 0.006067 & 0.005996 & 19 & 0.50 & 0.15 & 0.07 \\
\hline 31 & 32 & 0.001933 & 0.002253 & 20 & 0.50 & 0.21 & 0.10 \\
\hline 32 & 33 & 0.002123 & 0.003301 & 21 & 0.10 & 0.06 & 0.04 \\
\hline 8 & 34 & 0.012453 & 0.012453 & 24 & 0.50 & 0.00 & 0.00 \\
\hline 9 & 35 & 0.012453 & 0.012453 & 26 & 0.50 & 0.00 & 0.00 \\
\hline 12 & 36 & 0.012453 & 0.012453 & 30 & 0.50 & 0.00 & 0.00 \\
\hline 18 & 37 & $0 . .003113$ & 0.003113 & 37 & 0.50 & 0.00 & 0.00 \\
\hline 25 & 38 & 0.003113 & 0.002513 & 10 & 0.10 & 0.00 & 0.00 \\
\hline
\end{tabular}




\section{Appendix B}

\section{Exhaustive Search Algorithms}

\subsection{Steps for minimum $P_{L}$}

step 1 : Load the data_base files

step2 : Assign $\mathrm{k}=1, \min \_$loss $=P_{L W O D G}$, and $k_{\max }=$ no. of set of data.

step3 : Read $P_{L}(k), N V L V(k), N L C L V(k), P_{D G}(k), P_{\text {int }}(k)$.

step4 : if $\mathrm{P}_{\mathrm{L}}(\mathrm{k})>$ min_loss go to step8.

step5 : if $(\mathrm{NVLV}(\mathrm{k}) \neq 0)\|(\mathrm{NLCLV}(\mathrm{k}) \neq 0)\|\left(P_{D G}>P_{\text {int }}\right)$ go to step 8.

step6 : $\min \_$loss $=P_{L}(k)$

step7 $: k_{\text {minpl }}=k\left(k_{\text {minpl }}\right.$ is the value of $\mathrm{k}$ corresponding to minimum $\left.P_{L}\right)$.

step8 : if $k=k_{\max }$, go to step 10 .

step9 : $\mathrm{k}=\mathrm{k}+1$, go to step3.

step10: Print DG_bus $\left(k_{\text {minpl }}\right), P_{D G}\left(k_{\text {minpl }}\right), Q_{D G}\left(k_{\text {minpl }}\right), P F_{D G}\left(k_{\text {minpl }}\right), P_{L}\left(k_{\text {minpl }}\right), Q_{L}\left(k_{\text {minpl }}\right), S_{\text {int }}\left(k_{\text {minpl }}\right), P_{\text {int }}\left(k_{\text {minpl }}\right), Q_{\text {int }}\left(k_{\text {minp }}\right), S_{\text {sys }}\left(k_{\text {minpl }}\right)$, $N V L V\left(k_{\text {minp }}\right), N L C L V\left(k_{\text {minp }}\right), \operatorname{PLI}\left(k_{\text {minpl }}\right), Q L I\left(k_{\text {minp }}\right), V P I\left(k_{\text {minpl }}\right), L C I\left(k_{\text {minp }}\right)$.

step11: go to step 1 till all the files are considered.

\subsection{Steps for minimum $S_{\text {int }}$}

Step1 : Load the data_base files

Step2 : Assign $\mathrm{k}=1, \min _{-} S_{\text {int }}=S_{\text {int WODG, }}$ and $k_{\max }=$ no. of set of data.

Step3 : Read $S_{\text {int }}, P_{L}(k), P_{L W O D G}, P_{\text {int }}(k), P_{D G}(k), N V L V(k), N L C L V(k)$.

Step4 : if $S_{\text {int }}(\mathrm{k})>$ min_ $S_{\text {int }}$, go to step9.

Step5 : if $\left(P_{L}(k)>P_{L W O D G}\right) \& \&\left(P_{D G}(k)>P_{\text {int }}(k)\right.$, go to step9.

Step6 : if $(\mathrm{NVLV}(\mathrm{k}) \neq 0) \|(\mathrm{NLCLV}(\mathrm{k}) \neq 0)$, go to step 9.

Step7 : $\min _{-} S_{\text {int }}=S_{\text {int }}(k)$

Step8 $: k_{\text {minsi }}=k\left(k_{\text {minsi }}\right.$ is assigned the value of $\mathrm{k}$ corresponding to minimum $\left.S_{\text {int }}\right)$.

Step9 : if $k=k_{\max }$, go to step 11 .

Step10: $\mathrm{k}=\mathrm{k}+1$, go to step3.

Step11: Print DG_bus $\left(k_{\text {minsi }}\right), P_{D G}\left(k_{\text {minsi }}\right), Q_{D G}\left(k_{\text {minsi }}\right), P F_{D G}\left(k_{\text {minsi }}\right), P_{L}\left(k_{\text {minsi }}\right), Q_{L}\left(k_{\text {minsi }}\right), S_{\text {int }}\left(k_{\text {minsi }}\right), P_{\text {int }}\left(k_{\text {minsi }}\right), Q_{\text {int }}\left(k_{\text {minsi }}\right), S_{s y s}\left(k_{\text {minsi }}\right)$, $N V L V\left(k_{\text {minsi }}\right), N L C L V\left(k_{\text {minsi }}\right), P L I\left(k_{\text {minsi }}\right), Q L I\left(k_{\text {minsi }}\right), V P I\left(k_{\text {minsi }}\right), L C I\left(k_{\text {minsi }}\right)$.

step12: go to step 1 till all the files are considered.

\section{References}

Ackermann T., Andersson G., Soder L., 2001. Distributed generation: a definition. Electric Power Systems Research, vol. 57, no. 3 pp. 195-204.

Algarni Ayed A. S. and Bhattacharya Kankar, 2009. Disco operation considering DG units and their goodness factors. IEEE Trans. Power System, vol. 24, no. 4, pp.1831-1840.

Atwa Y.M., El-Saadany E. F., Salama M.M.A., and Seethapathi R, 2010. Optimal renewable resources mix for distribution system energy loss minimization," IEEE Trans. Power Syst., vol. 25, no. 1 pp. 360-370.

Chiradejaand P., and Ramakumar R ., 2004. An approach to quantify the technical benefits of distributed generation. IEEE Trans. Energy Convers., vol.19, no .4, pp. 764-773.

Dent C. J., Ochoa L. F., and Harrison G. P., 2010. Network distributed generation capacity analysis using OPF with voltage step constraints," IEEE Trans. Power Syst., vol. 25, no. 1 pp. 296-304..

El-Khattam W., and Salama M. M. A., 2004. Distributed Generation Technologies, Definitions and Benefits. Electric Power System Research Vol. 71, no. 2, pp. 119-128.

El-Khattam W., Hegazy Y.G., and Salama M.M.A.., 2005. An integrated distributed generation optimization model for distribution system planning," IEEE Trans., Power System, vol 20, no. 2, pp.1158-1165.

Gozel T., Hocaoglu M. H., Eminoglu U., and Balikci A., 2005. "Optimal placement and sizing of distributed generation on radial feeder with different static load models," in Proc. Int. Conf. Future Power Systems, pp. 1-6.

Harrison G. P., Piccolo A., Siano P., and Wallace A. R., 2008. Hybrid GA and OPF evaluation of network capacity for distributed generation connections. Elect. Power Syst. Res., vol. 78, no. 3, pp. 392-398.

Hung D. Q., Mithulananthan N., and Bansal R. C., 2010. Analytical expression for DG allocation in primary distribution network," IEEE Trans. Energy Convers., vol. 25, no. 3, pp. 814-820. 
IEEE Task Force on Load Representation for Dynamic Performance, 1993. "Load representation for dynamic performance analysis," IEEE Trans.Power Syst., vol. 8, no. 2, pp. 472-482.

Kumar A., and Gao W., 2010. Optimal distributed generation location using mixed integer non-linear programming in electricity markets. IET Gen. Trans. \& Distrib. Vol 4, no. 2, PP. 281-298.

Kumar Vishal, Kumar Rohith., Gupta Indra, and Gupta Hari Om, 2010. DG Integrated approach for service restoration under cold load pickup," IEEE Trans. Power Del., vol. 25, no. 1, pp. 398-406.

Ochoa L. F., Feltrin A. Padilha, and Harrison G. P., 2008. Time-series based maximization of distributed wind power generation integration," IEEE Trans. Energy Conv., vol. 23, no. 3, pp. 968-974.

Payasi Rajendra P., Singh Asheesh K, and Singh Devender, 2011. "Review of Distributed Generation Planning: Objectives, Constraints and Algorithms," Int. Journ. of Sc., Engg, and Technology, Vol. 3, No. 3, pp. 133-153.

Pepermans G., Driesen J., Haeseldonckx D., Belmans R., D’haeseleer W., 2005. Distributed generation: definition, benefits and issues. Energy Policy, vol. 33 pp. 787-798.

Qian Kejun, Zhou Chengke, Allan Malcolm, and Yuan Yue, 2011. "Effect of load models on assessment of energy losses in distributed generation planning," Int J. Electrical power and Energy Systems, , 33, pp 1243-1250.

Singh Deependra, Singh Devender, and Verma K. S., 2009. Multiobjective Optimization for DG Planning with Load Models," IEEE Trans. Power System, vol. 24, no. 1, pp. 427-436.

Singh Devender, Mishra R. K., and Singh Deependra, 2007. "Effect of Load Model in Distributed Generation Planning," IEEE Trans. Power. Syst., vol. 22, no. 4, pp. 2204-2212.

Vovos P. N. and Bialek J. W., 2005. "Direct incorporation of fault level constraints in optimal power flow as a tool for network capacity analysis," IEEE Trans. Power Syst., vol. 20, no. 4, pp. 2125-2134.

Vovos P.N.., Harrison G.P.., Wallace A.R.., Bialek J.W., 2005. "Optimal power flow as a tool for fault level-constrained network capacity analysis,” IEEE Trans. Power Syst., vol. 20, no.2, pp. 734-741.

Zhu D., Broadwater R. P., Tam K. S., Seguin R, and Asgeirsson H., 2006. Impact of DG placement on reliability and efficiency with time-varying loads," IEEE Trans. Power Syst., vol. 21, no. 1 pp. 419-427.

\section{Biographical notes}

Rejendra Prasad Payasi received the B.E. degree from Govt. Engineering College, Rewa (M.P.), India, in 1980, the M. Tech. degree in Electrical Engineering from Institute of Technology (IT), Banaras Hindu University (BHU), Varanasi, India , in 1983. Currently he is pursuing the Ph. D. degree in Electrical Engineering under QIP from Motilal Nehru National Institute of Technology, Allahabad, India. He is associate Professor with the Department of Electrical Engineering, Kamla Nehru Institute of Technology, Sultanpur (U.P.), India. His research interests are distributed generation planning, distribution system analysis, and genetic algorithms application in power system.

\footnotetext{
Asheesh K. Singh received the B.Tech. degree from HBTI, Kanpur, India, the M.Tech. degree from the REC, Kurukshetra, India, and the Ph.D. degree from the Indian Institute of Technology, Roorkee, India, in 1991, 1994, and 2007, respectively. Since 1995, he has been on the academic staff of MNNIT, Allahabad, India, where he is now Associate Professor with the Department of Electrical Engineering. His research interests are application of soft computing techniques in power systems, distributed generation, power quality and reliability.

Devender Singh received the B. E. degree in electrical engineering from Sardar Vallabhbhai National Institute of Technology, Surat, India, in 1993, the M.E. Degree in electrical engineering from Motilal Nehru National Institute, Allahabad India, in 1999, and Ph.D. in electrical engineering from Institute of Technology (IT), Banaras Hindu University (BHU), Varanasi, India. Presently, He is Professor with the Department of Electrical Engineering, IT, BHU. His research interests are distributed generation planning, state estimation, short term forecasting, and AI application in power system.
}

Received January 2012

Accepted February 2012

Final acceptance in revised form March 2012 